2015-01-02

\title{
Unsettling sustainability: the poetics of discomfort
}

\author{
Bloomfield, Mandy
}

http://hdl.handle.net/10026.1/10276

10.1080/14688417.2014.982674

Green Letters

Informa UK Limited

All content in PEARL is protected by copyright law. Author manuscripts are made available in accordance with publisher policies. Please cite only the published version using the details provided on the item record or document. In the absence of an open licence (e.g. Creative Commons), permissions for further reuse of content should be sought from the publisher or author. 


\section{Unsettling Sustainability: The poetics of discomfort}

For all its ostensibly worthy connotations, the concept of sustainability risks perpetuating modalities of thinking which are inadequate to the profound and urgent epistemological and ontological challenges of ecological crisis. This paper offers a critique of this concept, and suggests that literary works have a role to play in unsettling some of its problematic logics. Drawing on the experimental poetic techniques of Maggie O'Sullivan and Allen Fisher, it proposes that in different ways their writing embodies a poetics of discomfort which productively unsettles cosy narratives of environmental sustainability.

Keywords: sustainability; experimental poetics; Maggie O’Sullivan; Allen Fisher; Stacy Alaimo; climate change

How are the literary humanities relevant to discussions of sustainability? What could scholars and practitioners of the literary arts possibly have to say about a discourse which seems predominantly concerned with pragmatic, rather than aesthetic or cultural issues? And what, if anything, is the relation between works of literature and the discourses and practices of sustainability? During the 2013 symposium on Literature and Sustainability in Lampeter, Wales which explored such questions and gave rise to this special issue of Green Letters, Graham Huggan helpfully outlined two, often conflicting, ways of approaching the day's focal topic; the first broadly sees sustainability in terms of political praxis, the second as a theoretical conundrum. To read literature against sustainability understood in this first way, he (and others) suggested, was to risk instrumentalising aesthetic works for political purposes. Perhaps, then, literary perspectives might most fruitfully perform a theoretical investigation of this culturally important but contested concept. This is the approach 
that this paper takes, by first of all raising some key concerns about the assumptions and logics of the sustainability concept and then moving on to discuss some examples of contemporary poetry which offer opportunities for a productive unsettling of these logics. I examine samples of the work of experimental writers Maggie O’Sullivan and Allen Fisher, because their work is interested in exploring and expanding vocabularies, epistemologies and ontologies pertinent to ecological questions. The work I examine doesn't address issues of sustainability directly; these are not poems that are explicitly 'about' recycling or carbon emissions or biodiversity, for example. Rather, this poetry performs an investigatory poetics which has implications for the modes of thought involved in the concept of sustainability. In particular, it formally embodies a poetics of discomfort, which unsettles cosy, optimistic narratives of sustainability.

\section{Sustainability and its shortcomings}

For all of its laudable practical aims, the concept of sustainability is nebulous, highly conflicted and rooted in a number of problematic assumptions. On the face of it, the ubiquitously-cited definition from the 1987 UN 'Brundtland Report', Our Common Future, appears to state an aim to which any responsible individual or collective should want to commit: 'development that meets the needs of the present without compromising the ability of future generations to meet their own needs' (United Nations 1987, Chapter 2.I.1.). The report goes on to delineate 'two key concepts':

- The concept of 'needs', in particular the essential needs of the world's poor, to which overriding priority must be given; and 
- The idea of limitations imposed by the state of technology and social organization on the environment's ability to meet present and future needs. (United Nations 1987, Chapter 2.I.1.)

Since the Brundtland definition has become paradigmatic for understandings of sustainability in a vast range of contexts, it provides a good place to start investigating the concept. One of the many problems with this definition, especially when lifted out of context (as it is so often), is that it is so vague and capacious that the concept it proposes is readily watered down and appropriated for a range of agendas. The World Bank's webpages on the topic, for example, revolve around the central claim that 'Sustainable development recognizes that growth must be both inclusive and environmentally sound to reduce poverty and build shared prosperity for today's population and to continue to meet the needs of future generations'(The World Bank 2014). This statement invokes Brundtland's rhetoric, and its first 'key concept', along with the 'three pillars' of interconnected economic, social and environmental factors. But here, it is assumed that 'development' means economic growth (an emphasis which is also very prominent in the Brundtland report), whilst the World Bank's neoliberal agenda and its practice of imposing prescriptive loan conditions on borrowers in the 'developing world' are often very clearly incompatible with social and environmental sustainability. Furthermore, many green thinkers would argue that the very notion of 'growth' cannot be so easily balanced with environmental concerns (Dobson 2007, 53-62). Meanwhile, in another appropriation of the Brundtland formula, the multinational supermarket giant Walmart $®$ claims to be leading the way in sustainable business, declaring that 'our actions have the potential to save our customers money and help ensure a better world for generations to come', before outlining three 'sustainability goals' concerning energy, waste and 'products that sustain people and the environment' (Walmart@ 2014). 'Needs of the present' are 
here dubiously interpreted as 'sav[ing] our customers [in the West] money' (Walmart@ 2014). And the multiple rhetorical gestures towards responsible environmental policies and ethical labour practices ring resoundingly hollow when made by a corporation whose business model centrally involves exploiting the cheap labour of impoverished populations, shipping inconceivable quantities of ephemeral and inessential goods long distances, and selling them in huge out-of-town stores.

If ideas of sustainability can be so easily co-opted and moulded to suit such agendas, then this term cannot be used uncritically. A fundamental question to ask, as Andrew Dobson $(2007,29)$ indicates, is 'What is to be sustained?' For The World Bank, Walmart ${ }^{\circledR}$ and to a large extent the Brundtland Commission, the answer is predominantly economic growth rooted in our current system of late capitalism, but ostensibly at slightly lower cost to the environment than at present. ${ }^{1}$ In mainstream versions of sustainability, as the Brundtland definition helps to demonstrate, 'the environment' is imagined as a sustaining background to human societies, as a storehouse to furnish the needs of present and future (human) generations, and a set of resources upon which technology and society might act to extend the 'limitations' of available reserves. A deeper green response to Dobson's fundamental question would offer a rather different perspective, emphasising the 'limits to growth', as the Club of

\footnotetext{
${ }^{1}$ Relevant here is the notion that, as Slavoj Žižek is fond of saying, 'it's much easier to imagine the end of all life on earth than a much more modest radical change in capitalism'(Taylor 2005). This oft-cited formulation's origins are hard to trace; Žižek echoes Frederic Jameson's earlier and less specific remark, 'it's easier to imagine the end of the world than the end of capitalism' $(2003,76)$. But since Jameson prefaces this with the words 'Someone once said' $(2003,76)$, and doesn't specify who that someone was, it is difficult to trace the initial expression of the sentiment.
} 
Rome's key thesis of 1974 put it. Such a position broadly argues that 'technology on its own cannot solve the limits to growth problem' and that what is needed in the sustainable society is 'profound changes in social thought and practice - changes in human values, ideas of morality and associated practices'(Dobson 2007, 57). One of these shifts in thinking and practice involves a recognition 'that the environment has an intrinsic value in the sense that its value is not exhausted by being a means to human ends - and even if it cannot be made a means to human ends it still has value'(Dobson 2007, 15). Whilst such a stance seems more ethically palatable than neoliberal versions of sustainability, I want to suggest that, whether of the 'shallow' or the 'deep' (Naess 1973) variety, the discourse of sustainability nevertheless has a number of troubling theoretical blind spots.

The first of these is that sustainability discourse broadly tends to imagine "the environment' as if it were a realm distinct from 'the human'. As Stacy Alaimo puts it in her contribution to a recent special issue of PMLA on the sustainable humanities, 'the epistemological stance of sustainability, as it is linked to systems management and technological fixes, presents a rather comforting, conventional sense that the problem is out there, distinct from one's self. Human agency and master plans will get things under control' (Alaimo 2012, 561). This tendency to put 'the natural world' at a distance isn't confined to instrumentalist versions of sustainability. However hard deep ecology might try to critique human/nature binaries, the argument that nature has a 'independent' and 'intrinsic' value in-itself, and that 'human interference in the nonhuman world is excessive'(Naess and Sessions [1984] 1995, 50 my emphasis) runs the risk of reinforcing the separation of 'nature' from human spheres of life. But as numerous commentators from Bill McKibben to Bruno Latour and Timothy Morton have argued, the challenge for properly ecological modes of thinking is to abandon 
the idea of 'nature' as a realm 'out there'. Stacy Alaimo argues in her book Bodily Natures $(2010,20)$ that our contemporary world of climate change, globalised cultural encounters and 'trans-corporeal' enmeshment in a more-than-human world demands 'a recognition not just that everything is interconnected but that humans are the very stuff of the material, emergent world'. This also means that agency cannot be imagined as exclusively, or even primarily, human, as the narratives of sustainable development assume. Instead, agency becomes a much more complex matter of 'human-non-human assemblages'(Bennett 2010, 36) or, even more powerfully, 'intraaction'(Barad 2007, 33) of co-constituting entities and processes.

A second major problem with ideas of sustainability is that they rest on an assumption that there is a fairly stable ecological state, or 'balance of nature' to sustain, if only human societies could act more responsibly. In his essay in the aforementioned PMLA special issue on the sustainable humanities, Steve Mentz $(2012,586)$ points out that 'behind our shared cultural narratives of sustainability sits a fantasy about stasis, an imaginary world in which we can trust whatever happed yesterday will keep happening tomorrow'. This is a fantasy which the sciences of ecology simply don't support. From at least the 1970s onwards, this field has generally moved away from notions of equilibrium-seeking ecosystems towards disequilibrium models which posit that, as prominent proponent of this view Daniel Botkin $(1990,9)$ argues, 'change now appears to be intrinsic and natural at many scales of time and space in the biosphere'. Such an idea, he acknowledges, 'opens a Pandora's box of problems for environmentalists... once we have acknowledged that some kinds of change are good, how can we argue against any alteration of the environment?'(10). Botkin ends up putting a positive spin on this problem, proposing that humans should re-imagine ourselves as engineers or conductors who monitor and 
affect the speed of ecological change (191-2). This approach has its problems. Donald Worster $(1994,416)$ points out that it then becomes difficult to determine what is 'unnaturally rapid or novel under so restless a sky'. Furthermore, and perhaps even more importantly, the idea of humans of conductors of ecological processes falls once more into the hubristic trap of assuming that humans have the monopoly on agency. Nevertheless, disequilibrium models of ecology do productively unsettle complacent notions of a 'balance of nature' which might be maintained through careful management or ethical adjustments.

Such a notion seems even less tenable in a context in which local and global ecological systems are already profoundly affected by mass extinctions, industrial pollution and climate change. As ecologists Debra Peters, Brandon Bestelmeyer and Alan Knapp $(2011,261)$ put it, 'Human influences on ecological drivers are increasingly recognized as dominant processes across a range of spatial and temporal scales'. In 2013, the Fifth Assessment Report of the Intergovernmental Panel on Climate Change (IPCC) confirmed, with higher degrees of certainty than ever before, that 'warming of the climate system is unequivocal'(IPCC 2013,2), that 'many of the observed changes are unprecedented'(2), that 'radiative forcing' driven by anthropogenic greenhouse gases continues to grow (12-14) with concentrations of carbon dioxide in the atmosphere reaching 400 parts per million in 2013 , and that 'it is extremely likely that human activity has been the dominant cause of observed warming since the mid- $20^{\text {th }}$ century'(15). The summary report also finds that 'Most aspects of climate change' including ocean acidification, irreversible loss of polar ice, and extreme weather events, 'will persist for many centuries even if emissions of $\mathrm{CO}^{2}$ are stopped'(25). As I write, in the winter of 2013-14, one such 'extreme weather event', an irregular 'polar vortex' linked to a warming Arctic, has gripped North 
America in extremes of cold, and its wider effects are being felt across the Atlantic in the UK in the form of exceptionally heavy rain and flooding. Is this a symptom of climate change? Experts cannot say, with any level of certainty. In an official video posted on the White House website, Barack Obama's Science and Technology Advisor, John Holdren (2014) explains that 'no single weather episode can either prove or disprove global climate change' but that such extreme events form part of 'a pattern we can expect to see with increasing frequency as global warming continues'. When even the White House is acknowledging huge changes in global and regional climate, and the radical uncertainties this entails, it is surely time to relinquish fantasies of ecological homeostasis.

That such radical and rapid changes in the biotic world as climate change are already underway and, as the IPCC report indicates, will continue even if radical action were to be taken now, also undercuts the optimistic teleological narrative of sustainability. A third difficulty with the sustainability narrative, then, is that it does indeed take the form of a certain kind of narrative, one in which changes made to our ways of thinking and living in the present, or the near future, will ensure a viable ecological, social and economic state of affairs for 'future generations'. That the 'sustainable society' is always yet-to-come, whilst multiple-dimensional ecological emergency is already happening - has already happened - ought to give pause for thought. Timothy Morton $(2013,14)$ has argued recently that the contemporary moment is 'the time of hyperobjects', entities 'massively distributed in time and space relative to humans'(1) such as global climate change and forms of waste such as plutonium and polystyrene which have entered ecological systems but won't have degraded within an imaginable stretch of time. Hyperobjects outstrip our conceptual and imaginative powers; they evade our material and conceptual grasp, and their 
multiple, interacting effects are unpredictable. But they are nevertheless more real than the phenomena we can detect and imagine. Comforting and consoling ideas of 'sustainable' futures are profoundly undercut by the fact that hyperobjects are already here and now, materially affecting our reality. Thus these entities produce a strange temporality, not only in that they are 'massively distributed in time' in ways difficult to conceptually process, not only because they make the possible futures of life on earth so uncertain, but also because the hyperevent of ecological emergency will already have been happening and has already been happening in ways that haven't yet been adequately recognised.

I do not want to be misconstrued here as proposing the abandonment of practical measures that have any chance of minimising damaging impacts on wider ecologies within which humans are embedded. But I do believe that the real, present and unpredictable ecological emergencies of the contemporary moment require more supple modes of ecological imagining and ethical orientation than the habituated modes of thought that concepts of sustainability risk perpetuating. How might literary works play a part in exploring this dilemma? I shall now turn to some examples of contemporary modernist poetry to explore this question because I think that this mode of writing performs formal moves which might offer glimpses of alternatives to comfortable narratives of sustainability. Indeed, such writing positively cultivates and explores discomfort through techniques which unsettle the privileged stability of lyric or narrative personae, eschew teleological thinking, explore 'otherness' and reflectively engage the vocabularies through which the material world is habitually negotiated. This work also formally embodies principles of unpredictable dynamism, uncertainty and incompleteness. Such poetic strategies, as I shall show, have implications for ecological thinking. 


\section{Of mutability and trans-corporeality}

The first writer whose work I wish to consider is Anglo-Irish poet Maggie O'Sullivan. An acute sensitivity toward ecological relationships, and the ethical responsibility these entail, has always been a shaping force in her practice, and especially so since she moved from London to the Yorkshire moors in 1988. In the words of the poet, '[1]iving in place in close relation beside other-than-human sentience has deepened my trust in the provisional, the precarious, in the precisions of the transient'(O'Sullivan and Olsen 2004). The poet imagines her rural environment not as a 'stable, enduring counterpoint to the disruptive energy and change of human societies' (Garrard 2004, 56), typical of traditional pastoral visions, but in terms of a sharpened sense of co-existence with other-than-human agencies which induces a commitment to dynamic contingency, instability and often discomforting and unpredictable transformations. Later in the interview, she expands: 'I feel part of a particular kind of multi-sonic/trans-somatic environment that is filled with other-thanhuman voicings/breathings /existences - that is always in flux, in-process, unhushed'(O'Sullivan and Olsen 2004). This sensibility resonates strikingly with Alaimo's notion of trans-corporeality, which, by emphasizing the material exchanges between a variety of 'bodily natures', 'may catalyze the recognition that the environment, which is too often imagined as inert, empty space, or as a resource for human use, is, in fact, a world of fleshy beings with their own needs, claims, and actions'(2010, 2). Far from an 'inert' ground for sustaining human development, 'the environment' is understood here as a mobile, multidimensional terrain of material agencies and interchanges. Indeed, in this thinking, as O'Sullivan's poetics helps to emphasise, 'the environment' is other life forms. 
O'Sullivan's ecological thinking thus contests the notion, so often at work in sustainability discourse, of an 'environment' that is distinct from 'us' and passively subject to human actions upon it. Her poetry instead proposes profoundly 'transcorporeal' understandings of ecological relationships and agential forces, and it does so in its very forms and manipulations of language. Although one could draw on many of her poems as exemplary in this respect, for my purposes here a single pertinent poem shall suffice: 'Of Mutability', published in what is probably O'Sullivan's best-known collection, In the House of the Shaman (1993), in a section entitled 'Kinship with Animals'. As these titles alone indicate, this is a poem which articulates an aspiration to explore ecological relationships and processes of transformation. ${ }^{2}$ The following lines demonstrate the poet's 'trans-somatic' sense of environment:

\section{SNOUTILY \\ PAW seizes - \\ butterbleeds among sunken}

\section{SHADE}

skidded Skull's metal teething -

Crag Stresses, Root Sicknesses -

${ }^{2}$ O'Sullivan's 'shamanic' orientations are part of this emphasis on the transformative, although, as an aside, some qualification about her understanding of shamanism seems necessary. Joseph Beuys is an influential figure for her, and she uses one of his statements as an epigraph to the section in which the poem under discussion features. But she is wary of shamanism's 'new age'(O'Sullivan and Thurston 2011, 247) connotations and its personist investment in the figure of the shaman. What she draws from Beuys is an insistence on dynamism and change, and the potentially 'therapeutic' (Beuys' term, quoted in O'Sullivan 1993, 28) power of materials, including language. 
they are one to the body

(O’Sullivan 1993, 37)

As with any O'Sullivan poem, it is difficult to say what this sequence is 'about'. But it is possible to say that it moves between images of animal, vegetal and geological activity and interrelation, all of which, the poem indicates, 'are one to the body'. The notion of the 'body' that this sequence offers, then, is that of a transcorporeal, or in O'Sullivan's terms 'trans-somatic' entity, an assemblage comprising specific qualities, dynamic processes and multiple, possibly competing forces. There is little sense of figure and ground here, no representation of a distinct 'body' inhabiting an environment; rather than functioning as background, or surrounding medium, or a set of resources to be carefully managed, 'the environment' is the very material of 'the body'.

O'Sullivan's language forms therefore enact an ontological stance that troubles the separation between 'nature' and human spheres of life upon which both 'shallow' and 'deep' sustainability discourses have tended to lean. The poetry partly achieves this through the eschewal of transcendent perspectives, situating attention among the sonic and visual contortions of the poetic field. That the poem is offered as a field - a relational arrangement of sounds, semantic effects and visual components is also significant. As I have argued elsewhere ([name of author removed] 2013, 1323), O'Sullivan's poetry draws on and extends the legacy of the post-war 'open field' poetics of Charles Olson, and especially Robert Duncan, in which the poem-as-field investigates embodied relations with wider social and physical worlds. Michael Davidson $(2012, \mathrm{xv})$ says in relation to Duncan's poetics, 'The open field is both an 
imperative about poetry's unfettered exploration of image, sound, and logos and a stance toward the organic unfolding of biological and social life'. O'Sullivan's field of juxtaposed language materials animate sonic, spatial and semantic exchanges that evoke ecological processes and modalities of interrelatedness. For example, the distressingly 'skidded Skull's metal / teething - ' is yoked to the geological tensions of 'Crag Stresses' and the vegetal malady of 'Root Sicknesses'. This linkage occurs not only through the semantic accumulations of 'skidded', 'teething', 'Stresses' and 'Sicknesses', suggesting a variety of traumatic physical struggles, but also through the physical gesture of the long, Dickinsonian dash, spatial clustering and the sound patterning of evolving 'sk', 'Sk', 'St' and 'Sick' sounds. Such exchanges embody an eco-logos of entangled embodied relation.

As this specific example might begin to suggest, in O'Sullivan's poetry, transcorporeality doesn't necessarily entail a conception of ecological relation in terms of a happy, harmonious holism; trauma, deep violence, disease and struggle are often palpably present. The poem refuses to replace the 'comforting, conventional sense that the [environmental] problem is out there, distinct from one's self' (Alaimo 2012, 561) with cheering fictions of cosy intimacy and oneness. But at the same time, it would be inaccurate to assume that O'Sullivan's environments are always figured as irreparably damaged, apocalyptic or dystopian. Vitality and exuberance are also present here, as in a series of emphatic exclamations including 'FIRE-SINUSES! / MOONJIES! / PLAYSIES!'(O’Sullivan 1993, 39) in which a child-like play with sound and 'nonsense' conveys a sense of pleasure in the manipulation of aesthetic materials.

In both its troubling and its playful articulations, this poetry stretches towards models of encounter and ecological co-dependence for which we don't yet have 
adequate conceptual or representational equipment. Its unfamiliar language forms enact a poetic mode of enquiry into the possibilities for new kinds of cognitive and affective structures. O'Sullivan's neologisms, a characteristic feature of her work, provide a particularly apposite and condensed example of this activity. Of these neologisms, Peter Middleton $(2011,98)$ remarks that reading this poet's work is often like reading an 'unknown language just emerging into perception'. This is language in the act of transformation, or stretching toward forms of knowledge, states of being and events not yet quite cognised. O'Sullivan's poetic fields are thus often uncertain and precarious, even when the words that constitute them are recognisable or half recognisable. Consider the following:

\author{
Snipe. Ashet abraiding Bitters beak Conduction \\ crystal a common lacerated thickly Early Spring \\ That Came summering copple blunts, clyst \\ seedless Bomba dampling traces of human bit/ \\ triply stilled a bleeding means \\ a Dock \\ growing to \\ Begin.
}

(O’Sullivan 1993, 38)

Most of the individual words here can be looked up in a dictionary. An ashet is an archaic word from Scotland and Northern England for a large plate. To abraid is to awaken. Clyst is a Celtic word for river, and the name of a particular river in Devon. A copple is a conical form, more specifically a hill. Bomba isn't a word that generally features in dictionaries, but a quick internet search suggests it is a proper name which could designate an Ecuadorian musical style, a village in Belize, a Libyan city or the 
name of the most powerful atomic bomb ever detonated, Tsar Bomba, exploded in 1961 by the Soviet Union. Dampling (whilst yielding a host of dumpling recipes on the internet) does seem to be an O'Sullivan coinage, suggesting the action of damping, and also perhaps trampling or sampling, the ' 1 ' adding a sense of suppleness or rhythmic oscillation (as in stippling or suckling) to the word. But what might the sequence 'seedless Bomba dampling' signify? The word 'seedless' seemingly tranforms 'Bomba' here into some kind of sterile organism (conceivably one whose seedlessness is connected in some way with nuclear fallout) which performs a mysterious - or at least highly ambiguous - action of 'dampling'. And what is it that is being 'dampled' - 'traces of human bit/'? Which are? Such a scene is hardly imaginable, since the entities involved seem unidentifiable, and their actions indeterminate. Nor is the image of an 'Ashet abraiding' quite conceivable. Middleton $(2011,99)$ pertinently observes that in O'Sullivan's poetry, '[n]othing remains the same long enough to enable a truth claim to assert strong rights over the reader. Each line, each word, and sometimes each phoneme, mark shifts of being, changes of perspective, transformations of feeling, altered understanding, hits of new perception'.

By poetically stretching the capacities of language in its negotiations of ecological relations, this work formally disrupts notions of homeostasis or a 'balance of nature'. Indeed, as the title 'Of Mutability' might suggest, the poem that I have taken as my example is quite explicitly concerned with processes of change and transformation through interaction. The poem's epigraph further emphasises this concern:

\footnotetext{
"seeking the transmutation of metals seeking a word to make
} 
change."

(Canto LVIII - Ezra Pound)

(O’Sullivan 1993, 35)

In Pound's canto these lines are followed by the Chinese character for change or metamorphosis, and whilst the local reference seems to be to alchemy, the wider canto documents a number of 'weak' emperors of ancient China whose susceptibility to influence by concubines and eunuchs, Pound suggests, wrought destructive changes on their kingdoms. Such a tracking down of sources, however, won't (unlike in Pound's own work) cast much light on the poem's engagement with its own present cultural moment. What seems most important here is what this fragment suggests in its own present reincarnation within O'Sullivan's poem, where what is emphasised is a restless process of (perhaps repetitive) 'seeking', and a parallel between material transformations and a linguistic power of change. That O'Sullivan has altered the lineation and alignment of the quotation from Pound is also significant; the statement undergoes material and semantic shifts within its new context. The poem's title and epigraph, then, foreground processes of metamorphosis, and posit a link - or a contiguity at the very least - between a language of transformation and changes in the material world.

O’Sullivan's dynamic, indeterminately-careering, mutating language forms embody principles of fluidity and flux which make present within language a sense of visceral and sensuously experienced coexistence with others. From the material malleability of the single word to the constantly shifting dynamics of the larger sequence, the corpus of language itself is transformed, trans-corporeal. Furthermore, these poetic forms eschew transcendent perspectives and subsuming conceptual schema to wallow in language as living substance. A poem like 'Of Mutability' 
doesn't make 'sense', but rather sensuously embodies a presentness - a being-here of ecological processes, relations and transmutations, experienced in a resolutely nonteleological, non-hierarchical here-and-now. O'Sullivan's word forms hover at the borders of legibility - and go somewhat beyond intelligibility - stretching language's capacities as a mode of openness to ontological 'otherness'. Moreover, as Romana Huk $(2011,51)$ points out, ‘[w]hile it is true that O’Sullivan's work, like Derrida's, reverences l'invention de l'autre - the incoming of the other... - her sensual collisions between the physical incarnations of words and phenomena... make that incoming more stuttering, imperfect and therefore more immediate than anything dreamt of in Derrida's philosophy'. Whereas Derridean difference, understood in terms of linguistic play, posits an eternal deferral of this incoming, O'Sullivan's poetry materially affirms linkages between entities and temporalities, bringing alterities into sensory or experiential presence, if not into full articulation. In doing so, O'Sullivan's poetry complicates the very notion of 'otherness', infolding familiarity and strangeness, animality, vegetality, humanity, minerality, proposing 'a new Ecology in poetics that recognises the indeterminacy of speciation or exactness of words'(Middleton 2011, 120). O'Sullivan's material and semantic transformations of language perform a rethinking - and palpable re-experiencing - of 'environment'. In so doing, this work destabilises separations between (human) organisms and 'environment' and associated assumptions about human agency, as well as notions about ecological stability, which are so deeply embedded in sustainability discourse. Furthermore, it offers an affective sense of what alternative modes of being and understanding might feel like. O'Sullivan's poetry implicitly suggests that in a search for 'a word to make change', the term 'sustainability' might not be it. 


\section{Confidence in lack}

As for O'Sullivan, ecological concerns have long been part of the context for Allen Fisher's poetics. In a recent (unpublished) statement for a workshop on Ecology and Poetics at the University of Southampton in May 2013, Fisher offers a 'map of attentions'(2013) for the early and ongoing development of his ecological orientations. Points on this 'map' include concerns over nuclear testing and pesticides in the 1950s and early 1960s, his engagement with the ecologically-oriented poetry of Allen Ginsberg and Gary Snyder in the 1960s, Charles Olson's notion of the 'planet as home', the land art of the 60s and 70s, and the influence of his engagement with Fluxus and with Joseph Beuys, whose Free University Fisher attended in the mid 70s. Fisher also began engaging with scientific and philosophical discourses pertinent to ecological matters through encounters with publications such as Edward Goldsmith's The Ecologist journal (1970 - 2009) and Gregory Bateson's Steps to an Ecology of Mind (1972). That these are just a small number of Fisher's influences suggests the enormous and diverse range of his attentions. What I want to focus $m y$ attention on here is his intimate engagement with scientific discourses, and the implications of this for a rethinking of the concept of sustainability, most especially in the context of the uncertainties and unknowns of environmental change. Fisher's research ranges widely across the sciences; he is a regular reader of Nature, and many of his poetry collections end with bibliographies which include a large number of scientific articles and textbooks aimed at specialist and general readers. Where O'Sullivan's poetic language performs material transformations of language and bodies forth a sensory proximity of co-existing entities, Fisher often draws on scientific ideas and vocabularies drawn from his various sources to investigate the knowns and unknowns of the material world. 
Fisher's notion of 'confidence in lack' offers a way in to thinking about his mode of engagement with scientific discourses. In an essay of this name, he asserts that 'poetry, when it is at its most efficacious, cannot propose logic, as it is variously perpetuated in paternal and public thinking, and cannot aspire to coherence, as this is also prescribed'(2007a, 77). Poetry offers alternatives to public languages and in particular the imperatives of logic and coherence; its 'efficacy' lies not in provoking action but in opening up a space for glimpsing alternatives to knowledge understood in terms of rationality, consistency and certainty. In relation to this notion of 'confidence in lack', Fisher (82) writes

The trail leads into rudimentary understandings of quantum lack and the resulting confidence position, leads, as it does so, into the underlying topic of this paper which I first named, with a gobstopper in my mouth, truth, and second with a celebration of Keats' Negative Capability, 'when a man is capable of being in uncertainties, mysteries, doubts, without any irritable reaching after fact and reason.'

The allusions here are dense, and the prose slippery. But part of what Fisher is doing is placing together Keats' Negative Capability, which encapsulates poetic 'confidence in lack', with scientific ideas which posit a high degree of 'uncertainty, mystery, doubt'. (Indeed, throughout this essay he juxtaposes discussion of complex scientific ideas with statements about aesthetics.) The specific scientific connection, following Charles Olson's prior example $(1970,42)$, is to Heisenberg's uncertainty principle, which asserts that at a quantum level, it's impossible to measure a particle's momentum and its position simultaneously. Knowledge about one of these aspects of the quantum particle is always inaccessible at any one time. What this indicates about 
Fisher's poetics is not only that he embraces indeterminacy and a kind of felt knowledge as integral dimensions of aesthetic practice, but also that he sees poetry and science as parallel modes of enquiry - and as modes of knowing and investigating the world that talk to one another, albeit sometimes across great distances. Moreover, he sees both aesthetic and scientific practices as activities involving an acknowledgement of different kinds of uncertainty, incomplete knowledge, and even intrinsic contradiction or paradox.

To tease out the implications of 'confidence in lack' for ecological thinking, I shall now turn to an example from the 2007 collection Leans, the last book in his long project Gravity as a Consequence of Shape, which spans twenty-three years. All the poems in the collection appropriate, to some extent, scientific vocabularies, and references to broadly ecological concerns surface with differing degrees of emphasis. The different poems operate at various levels of entanglement with one another (such as repeated and altered lines and key terms, recurring personae and interconnected references to place). But perhaps the most obviously relevant poem for my concerns is 'Spinor', which negotiates the vocabularies, modes of knowledge and imaginaries of climate change, and it does so through by appropriating, transforming and interweaving language from specialist scientific papers (not all of which are directly related to climate change) and a popular scientific book about this issue, as well as other sources and Fisher's own poetic constructions, including almost-narratives of experiences relating to particular places.

'Spinor' begins with one such almost-narrative sequence. It is worth quoting most of the first stanza to give a sense of the kind of syntactic structures Fisher employs in this poem as a whole: 


\author{
Reverse thrust heard \\ across lake from \\ behind mountain \\ indicative of a \\ storm travels towards \\ hearers another \\ spot of rain on \\ storm edge felt on \\ an arm before it lifts \\ to empty a vodka sunshine \\ flies bring squint \\ seen and then felt \\ (2007b, 49)
}

In a reading given at Furzeacres in Devon, Fisher (2006) indicates that this poem relates to a particular place, Lake Winnipesaukee in New Hampshire, which he'd visited a couple of years before. Adjacent to the lake, he says, is a range of mountains, on the other side of which is an airfield which can't be seen from the lake edge. Even without this anecdotal frame, the first lines invoke such a scene, in which the 'reverse thrust' of a landing jet engine is heard 'across lake from/ behind mountain', but is experienced as 'indicative of a / storm'. The impending storm becomes an important element in a series of subject rhymes (a technique often used by Fisher) which draw together references to weather, climate, landscape and technological forces throughout. Here, the conflation of an incipient weather event and the 'reverse thrust' of a jet engine transform a 'natural phenomenon' into a natural-anthropogenic assemblage, which becomes linked through subject rhyme with references to climate change in subsequent stanzas.

The ominous, almost indefinable composite entity that haunts this poem resonates with Morton's notion of hyperobjects, (or indeed Bruno Latour's prior 
formulation of quasi-objects [Latour 1993, 55-59]) which impinge, ambiguously, on everyday experience, but which defy full conceptualisation. In this first stanza, the emphasis is on sensory perception of the ambiguous 'storm'; it is 'heard', its 'edge' is 'felt on/ an arm' by means of a 'spot of rain' and it (complexly and indirectly) 'bring[s] squint / seen and then felt'. And yet these fleeting perceptual impressions don't add up to direct perception, nor secure knowledge of the entity. Morton (2013, 48) points out that, because of they are 'nonlocal', hyperobjects can never be directly experienced:

When you feel raindrops, you are experiencing climate, in some sense. In particular you are experiencing the climate change known as global warming. But you are never directly experiencing global warming as such. Nowhere in the long list of catastrophic weather events... will you find global warming.

Fisher's poem explores just such a dilemma, its syntactical swerves and lexical ambiguities invoking the unsettlingly uncertain dynamics between perceptual experience and the complex assemblages that shape material reality on massive and minute scales in the anthropocene, but whose processes elude epistemological capture.

Thus this poem pursues 'confidence in lack' as a way of engaging such phenomena. It goes on to investigate some of the discourses through which knowledge about environmental change (and especially climactic change) circulates. The lines 'hottest year / since measurement began' echoe oft-occurring formulations in the media during exceptional spells of weather, whilst another phrase 'Trapped in ice over thousands of years'(Fisher 2007b, 49), lifted from Mayer Hillman's book about climate change and public policy, How We Can Save the Planet, refers to the 
science of gathering data about carbon dioxide in the atmosphere and past temperatures from ice cores. Fisher also appropriates a great deal of material from a number of specialist articles on various topics published in a single volume of Nature in 2004, the time of writing. Of particular interest is his use of an essay on uncertainties in climate change modelling, from where he appropriates phrases that are reformed into lines such as 'importance of benchmark of anthropogenic / climate change climate sensitivity'(49) and 'systematic exploration of uncertainties / the complex variety of processes / that actually determine climate sensitivity'(50). What seems to be common to all these examples is their concern with measurement, and the attempt to identify temporal points of reference against which to map trajectories of change. Fisher's poem incorporates this material not to convey facts about climate change, nor to question their validity, but to investigate the particular vocabularies through which this complex phenomenon is known. What is revealed above all is a deep anxiety about uncertainty. Whilst logic might dictate a mode of investigation that tries to find out unknown data, poetry's 'negative capability' pursues alternative routes.

Fisher's poem, then, doesn't aim to convey or seek out further information; rather, it is interested in exploring how to 'process / uncertainties' $(2007 \mathrm{~b}, 50)$ not in the sense of pursuing technological fixes or practical solutions for more sustainable futures, but in the sense of philosophical and affective 'processing'. In 'Spinor', recognisable specialist and popular scientific terminologies are interlaced with such dizzying constructions as 'Intact fear before refusal of violence / thought and infinity a / sponge of universe'(50), moments of fatal melancholy ('In bed the weather man / gives up / the ghost' [50]) and imputed loss of control ('wheel strain in scree / the fast departed grip'[50]). Through what Fisher describes as 'facture' - the breaking and 
remaking of materials derived from research - the poem performs complex forms of connection. Robert Sheppard $(2005,195)$ sees Fisher's work as exemplary of a poetics of 'creative linkage' which he reads as an ethical imperative to 'link the components of the daily catastrophe, along with all its ecstasies'. Sheppard's orientation isn't specifically ecological, but the emphasis on an ethics of dailiness here is instructive. Indeed, what characterises global ecological emergency is precisely the everydayness, banality, incremental material shifts and the 'slow violence' (to use Rob Nixon's term) that places the catastrophe at a temporal and spatial distance. Part of the challenge that 'Spinor' takes on is to acknowledge and investigate the palpable and intangible forms of this catastrophe as they impinge on everyday perception.

Fisher's collaging of 'found' and 'factured' language, his startling juxtapositions, disorienting syntactic swerves and compelling but ambiguous subject rhymes confront readers with the dazzling forms of complexity and interconnectivity of the daily emergency. Such 'creative linkage' constitutes the poem as a disorienting spatio-temporal structure, as its title might suggest; 'Spinor' is a term used in advanced maths and physics to denote a complex vector which produces (theoretical) spatio-temporal transformations. The poem thus embodies a form of dailiness in the 'age of the hyperobject'(Morton) in which one challenge is to 'process / uncertainties'(50) and unimaginable complexities. But far from inducing a sense of bewildered helplessness, Fisher's poems model a kind of linkage based not on straightforward causality but on speculative and uncertain inferred connections. This is 'confidence in lack' in which accepting contingency and a position of epistemological humility need not induce paralysis but instead suggests possibilities 
for incipient imaginaries formed through processes of discomfiting but 'creative linkage'(Sheppard 2005, 195).

The poetry of O'Sullivan and Fisher courts discomfort, whether in terms of semantics and sensory perception, or ontological and epistemological uncertainty. In so doing, such work unsettles cosy, optimistic narratives of sustainability. Contemporary environmental imaginaries need to reach beyond such comfort zones. As Lynne Keller $(2012,583)$ has pointed out, 'through a focus on expanding the resources and pushing the limits of language itself', linguistically experimental poetry might 'generate the kind of intellectual and imaginative equipment that can help us move toward futures less bound to the modes of thinking and being that have produced the mess in which we find ourselves'. Some of these modes of thinking - the human/environment distinction, the failure to acknowledge non-human agency, notions of a 'balance of nature' and teleological narratives of predictable futures - are embedded in the concept of sustainability, especially in the 'shallow' forms adopted by corporations, powerful organisations and governments, but also in some of its 'deeper' incarnations. 'Lulled into false / expectation / run out of comfort' (Fisher 2007, 49), the ecological emergency of the contemporary moment demands an unsettling of sustainability discourse as we currently know it.

\section{References}

Alaimo, S. 2010. Bodily Natures: Science, Environment, and the Material Self. Bloomington, Indiana: University of Indiana Press.

Alaimo, S. 2012. "Sustainable This, Sustainabile That: Posthumanism, and Unknown 
Futures.” PMLA 127 (3): 558-564.

Barad, K. 2007. Meeting the Universe Halfway: Quantum Physics and the

Entanglement of Matter and Meaning. Durham and London: Duke University Press.

Bennett, J. 2010. Vibrant Matter: A Political Ecology of Things. Durham and London:

Duke University Press.

*[Publication by the author to be added after peer review] 2013

Botkin, D. 1990. Discordant Harmonies: A New Ecology for the Twenty-First

Century. Oxford: Oxford University Press.

Davidson, M. 2012. "Forward.” In Robert Duncan, the Ambassador from Venus: A Biography, edited by Lisa Jarnot. xiii - xx. Berkeley: University of California Press.

Dobson, A. 2007. Green Political Thought. $4^{\text {th }}$ ed. London and New York: Routledge.

Fisher, A. 2007a. “Confidence in Lack.” In Poetry and Public Language, edited by Tony Lopez and Anthony Caleshu, 76-85. Exeter: Shearsman Books.

Fisher, A. 2007b. Leans. Cambridge: Salt Publishing.

Fisher, A. 2013. “Allen Fisher - Before the 1980s, a memoir." Unpublished statement for Poetry \& Ecology workshop, University of Southampton.

Fisher, A. 2006. "Reading at Furzeacres, Devon (UK) June 2006 from Gravity as a Consequence of Shape, Vols. 2 and 3 Introduction by Philip Kuhn.” Sound file of poetry reading. Pennsound Centre for Programs in Contemporary Writing, University of Pennsylvania. http://writing.upenn.edu/pennsound/x/Fisher.php

Garrard, G. 2004. Ecocriticism. London and New York: Routledge. 
Holdren, J. 2014. "The Polar Vortex Explained in 2 Minutes.” The White House. http://www.whitehouse.gov/photos-and-video/video/2014/01/08/polar-vortexexplained-2-minutes

Huk, R. 2011. In The Salt Companion to Maggie O'Sullivan. 36-70. Cambridge: Salt Publishing.

Intergovernmental Panel on Climate Change. 2013. "Climate Change 2013: The Physical Science Basis: Summary for Policymakers.” IPCC. http://www.ipcc.ch/report/ar5/wg1/docs/WGIAR5_SPM_brochure_en.pdf

Jameson, F. 2003. "Future City." New Left Review 21: 65-79.

Keller, L. 2012. “Beyond Imagining, Imagining Beyond.” PMLA 127 (3): 579-585.

Latour, B. 1993. We Have Never Been Modern. Translated by Catherine Porter.

Cambridge, Massachusetts: Harvard University Press.

Mentz, S. 2012. “After Sustainability.” PMLA 127 (3): 586-592.

Middleton, P. 2011 “"Ear Loads': Neologisms and Sound Poetry in Maggie

O'Sullivan's Palace of Reptiles." In The Salt Companion to Maggie O'Sullivan. 97122. Cambridge: Salt Publishing.

Morton, T. 2013. Hyperobjects: Philosophy and Ecology after the End of the World. Minneapolis and London: University of Minnesota Press.

Naess, A. 1973. “The shallow and the deep: Long-range Ecology Movement. A Summary." Inquiry 16 (1): 95-100.

Naess, A. and Sessions, B. [1984]. 1995. "Platform Principles of Deep Ecology.” In 
Deep Ecology: An Introductory Anthology, edited by Alan R. Drengson and Yuichi Inoue. 49 - 53. Berkeley, California: North Atlantic Books.

Nixon, R. 2011. Slow Violence and the Environmentalism of the Poor. Cambridge, Massachusetts: University of Harvard Press.

Olson, C. 1970. The Special View of History. Berkeley: Oyez.

O’Sullivan, Maggie. 1993. In the House of the Shaman. London: Reality Street.

O’Sullivan, M and Olsen, D. 2004. "Writing / Conversation: an interview by mail November - December, 2003.” How2 2.2. Accessed January 52013.

http://www.asu.edu/pipercwcenter/how2journal/archive/online_archive/v2_2_2004/cu rrent/workbook/writing.htm

Peters, D. Bestelmeyer. B. and Knapp, A. 2011. "Perspectives on Global Change Theory." In The Theory of Ecology, edited by Samuel M. Scheiner and Michael R. Willig. 261-281. Chicago and London: University of Chicago Press.

Sheppard, R. 2005. The Poetry of Saying: British Poetry and its Discontents 19502000. Liverpool: Liverpool University Press.

Taylor, Astra, dir. 2005. Zizek! Zeitgeist Films.

O’Sullivan, Maggie and Scott Thurston. 2011. “An Interview.”In The Salt Companion to Maggie O'Sullivan, 241-249. Cambridge: Salt Publishing.

United Nations. 1987. "Report of the World Commission on Environment and Development: Our Common Future.” UN Documents. http://www.undocuments.net/our-common-future.pdf 
Walmart@. 2014. "Environmental Sustainability.” Walmart®.

http://corporate.walmart.com/global-responsibility/environmental-sustainability

The World Bank. 2014. "Sustainable Development.” The World Bank.

http://www.worldbank.org/en/topic/sustainabledevelopment

Worster, D. 1994. Nature's Economy: A History of Ecological Ideas. $2^{\text {nd }}$ ed.

Cambridge: Cambridge University Press.

7190 words 